\title{
CDC Grand Rounds: Preventing Suicide Through a Comprehensive Public Health Approach
}

\author{
Corinne David-Ferdon, $\mathrm{PhD}^{1}$; Alex E. Crosby, $\mathrm{MD}^{1}$; Eric D. Caine, $\mathrm{MD}^{2}$; Jarrod Hindman, MS 3 ; Jerry Reed, PhD ${ }^{2,4}$; John Iskander MD ${ }^{5}$
}

Suicide in the United States is a major public health problem with approximately 42,000 reported suicides in 2014 among persons aged $\geq 10$ years ( 1 ). The overall suicide rate is increasing, with a $27 \%$ increase from 2000 (12.1 per 100,000 population) to 2014 (15.4 per 100,000) (Figure 1). Males, youths and young adults, and certain racial/ethnic groups have historically had higher rates of suicide. In 2014, suicide rates were approximately four times higher among males $(24.3$ per 100,000$)$ than females $(6.8$ per 100,000$)$, and suicide was the second leading cause of death among youths and young adults aged 10-34 years (1). Among persons aged 10-24 years, the 2014 suicide rate among non-Hispanic American Indian/Alaska Natives was 20.2 per 100,000, 1.9 times higher than non-Hispanic whites (10.5 per 100,000), 3.5 times higher than non-Hispanic blacks (5.8 per 100,000), and 3.7 times higher than Hispanics $(5.5$ per 100,000) (1). Adults aged 35-64 years are an emerging group at risk, with suicide rates increasing 33\% since 2000 and accounting for the largest proportion of suicides (1).

Suicide data severely underestimate the extent of the problem, with many more persons experiencing suicidal thoughts and making suicide plans and nonfatal suicide attempts. For example, among adults aged $\geq 18$ years in 2014 , for every one adult who died by suicide there were nine adults treated in hospital emergency departments for self-inflicted injuries, 27 who reported making a suicide attempt, and 227 who reported seriously considering suicide (Figure 2). Self-reports by youths also have shown a high prevalence of suicide risk behaviors. According to CDC's 2015 Youth Risk Behavior Survey, $17.7 \%$ of students in grades $9-12$ reported seriously considering suicide, and $8.6 \%$ reported attempting suicide during the 12 months before the survey (2). The percentages of students who reported seriously considering suicide and students who reported making a plan for attempting suicide increased significantly during 2009-2015 (2).

This is another in a series of occasional MMWR reports titled CDC Grand Rounds. These reports are based on grand rounds presentations at CDC on high-profile issues in public health science, practice, and policy. Information about CDC Grand Rounds is available at http://www.cdc. gov/cdcgrandrounds.

\section{Suicide Prevention Needs a Public Health Approach}

Suicide prevention has been based on a mental health treatment approach because clinical conditions (e.g., depression, anxiety, psychosis, or alcohol and substance dependence) are apparent among many who kill themselves (3). However, this approach only reaches small segments of the population who have identified risk factors and who can surmount treatment barriers, such as stigma and limited availability of or access to services (4). This orientation is also too limiting because most persons with mental health problems do not engage in suicidal behavior or die by suicide. First-time suicide attempts can be fatal, and suicide warning signs (e.g., depression, increased use of drugs or alcohol, or mood changes) can be common symptoms among nonsuicidal persons and not predictive of future suicide attempts or suicide. Thus, a treatment-only approach to prevention has limited impact on national rates of suicide and nonfatal suicidal risk behavior (5).

A public health approach adds a complementary, wider, and prevention-oriented focus that increases attention to the many factors across the lifespan that contribute to circumstances that promote suicidal thinking and suicide attempts. This approach offers opportunities to foster protective factors throughout a person's life, supporting ongoing prevention well before the prospect of suicide is imminent. CDC's National Violent Death Reporting System (NVDRS) currently operates in 32 states and pools data from multiple sources (e.g., death certificates, coroners/medical examiners, and law enforcement) to better describe the who, when, where, and how of violent deaths and precipitating life circumstances. These data highlight suicide prevention opportunities (G). NVDRS data show that most suicides have multiple precipitating conditions, such as depression, intimate partner problems, physical health conditions, financial challenges, and legal problems ( 7 ). Suicide risk factors also include personal or family experiences of violence (e.g., child abuse and neglect or family history of suicide) and broader community conditions, such as high crime rates, easy access by persons at risk to lethal means (e.g., large amounts of medication or unlocked firearm), and limited access to health and social services $(7,8)$. NVDRS data underscore that mental health treatment should not be the only prevention strategy; approximately $70 \%$ of suicide decedents were not receiving mental health services at the time of their death, and approximately $80 \%$ did not have 
FIGURE 1. Suicide rates per 100,000 persons, by age group (years) - United States, 2000-2014

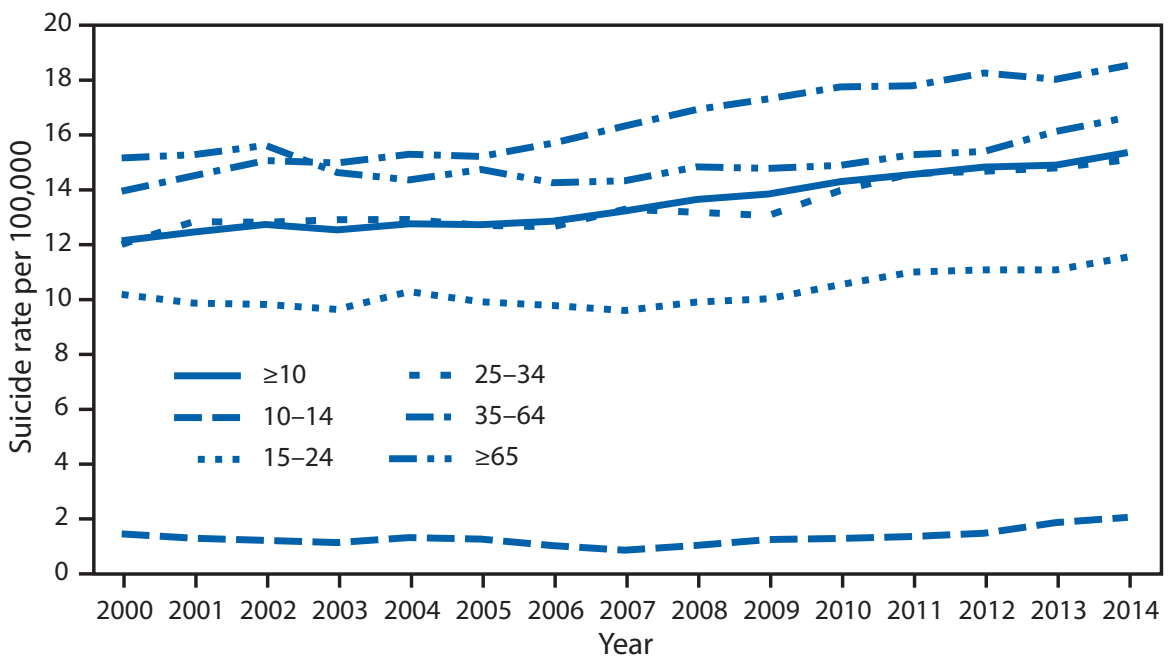

FIGURE 2 . Reported number of adults aged $\geq 18$ years who died by suicide, ${ }^{*}$ had self-harm injuries treated in emergency departments, ${ }^{\dagger}$ attempted suicide, ${ }^{\S}$ or seriously considered suicide $^{\S}$ — United States, 2014

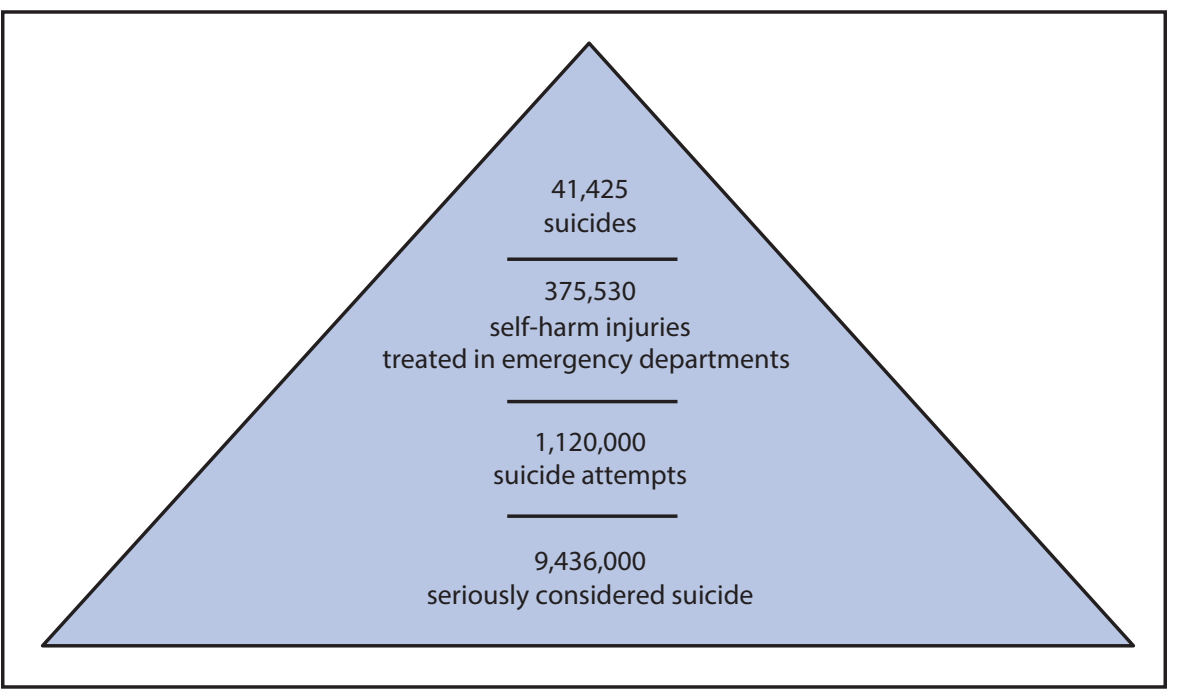

* National Vital Statistics System.

† National Electronic Injury Surveillance System-All Injury Program.

$\S$ National Survey on Drug Use and Health.

a known history of previous suicide attempts (7). Public health approaches, in contrast to clinical service delivery, can reach more persons and address many of the community-level factors that increase the potential for suicide, other forms of violence, and other health risk behaviors (e.g., drug and alcohol abuse). With its emphasis on a science-driven approach, the public health sector has the skills and expertise to collect and analyze relevant data, select and implement comprehensive prevention strategies, organize and integrate efforts involving diverse partners, and conduct rigorous and ongoing evaluation of interventions to successfully prevent complex adverse health events, such as suicide.

\section{Promising Suicide Prevention Approaches}

As recognized by the "National Strategy for Suicide Prevention: Goals and Objectives for Action, 2012," a comprehensive and coordinated prevention approach is needed (5). Promising models are available. For example, when fully implemented, the United States Air Force Suicide Prevention Program had 11 components that together increased community awareness of suicide, provided personnel training, encouraged help-seeking and help-accepting, enhanced confidentiality policies, sought to change social norms (e.g., reducing stigma for seeking mental health care), and created organizational accountability for implementing the program. This comprehensive approach was associated with substantial reductions in suicide rates $(33 \%)$, homicide $(51 \%)$, accidental death (18\%), and severe family violence (54\%) (9). Together for Life, a multicomponent suicide prevention program targeted to Montreal police, includes a publicity campaign directed at officers, training of all units and supervisors on suicide risk and how to give support, and a telephone helpline. The program was associated with a $79 \%$ reduction in suicide rates over 12 years while police in a comparison group experienced no statistically significant changes (10).

Prevention strategies at earlier stages of life also have shown promise. The Good Behavior Game is a classroom-based behavior management strategy for elementary schools that teaches youth to better control their emotions and work well with others through classroom rules, team activities, and positive reinforcement of appropriate behavior. This program has demonstrated reductions in antisocial behavior, smoking, and drug and alcohol use, as well as significant decreases in suicidal ideation and suicide attempts throughout childhood, adolescence, and young adulthood (11). Sources of Strength is a school-based program designed to reach all students regardless of their risk. Program components build connections between trained peer leaders and trusted adults who work together to seek to increase students' acceptance of help-seeking, healthy coping, and communication with adults while reducing the acceptability of suicidal and other harmful behaviors. Program benefits include increases in 
referrals for assistance, acceptability of help-seeking and helpaccepting, and enhanced perceptions of adult support, including among students with a history of suicidal ideation (12).

Increasing suicide rates demonstrate the need for more research to develop and implement prevention strategies that reach vulnerable groups. The National Action Alliance for Suicide Prevention, a public-private partnership of more than 200 organizations, systematically examined the state of the science to identify research gaps (13). One area identified as in need of more research is prevention approaches for adults aged 35-64 years. Consistent with this prioritized research agenda, CDC is rigorously testing innovative suicide prevention strategies (e.g., online, primary care-based settings) for middle-aged men.

A public health approach to suicide prevention is growing. The CDC-funded Injury Control Research Center for Suicide Prevention (ICRC-S) (http://suicideprevention-icrc-s.org/) is a collaboration of the University of Rochester Medical Center and the Education Development Center and draws on public health approaches to inform prevention activities at the state, regional, and national levels. ICRC-S is enhancing access to data to inform prevention planning, systematically defining and addressing challenges to preventing suicide among middleaged adults, examining issues (e.g., intimate partner violence, substance use, and economic challenges) that contribute to suicide, and using social media methods to define and reach groups at risk. The Colorado Department of Public Health \& Environment is using a public health approach to advance both research and practice to reach vulnerable groups, guided by its statewide public and private Suicide Prevention Commission and collaboration with ICRC-S and other national organizations. Activities include implementation and evaluation of online resources to engage men in help-seeking for suicide and mental health difficulties (http:// mantherapy.org/), education of emergency department clinicians regarding counseling caregivers of youths following a suicide attempt about reducing youths' access to lethal means (e.g., medication), and primary prevention with all youths regardless of known risk by prioritizing the Sources of Strength program in Colorado schools.

\section{Increasing Awareness of Suicide Prevention Opportunities}

Increasing communication about suicide and its risk factors, decreasing the stigma associated with seeking help from others, and strengthening access to support services to address emotional, interpersonal, and financial stressors are important prevention opportunities. The safe and appropriate discussion of suicide by traditional and online media can support prevention. Research-informed guidelines for reporting on suicide developed by partners in the United States and the
World Health Organization are designed to reduce the possibility of suicide contagion, provide hope, and raise awareness (Box). An evaluation of Austrian guidelines focused on subway suicides found a change in reporting practices (e.g., headlines and reports not sensationalized and reports not published on the front page) was associated with a $75 \%$ decrease in subway suicides and decreases were maintained over time (14).

Rapid access to trained crisis support personnel also can provide opportunities to substantially reduce persons' depression, suicidal thinking, and overwhelmed feelings (15). The National Suicide Prevention Lifeline (1-800-273-TALK) connects callers (1.5 million in 2015) with counselors in their local area through a network of 160 community crisis centers and offers specialized support to veterans, Spanish speakers, and online users (http://www.suicidepreventionlifeline.org/). National reductions in suicide are possible by using surveillance data (e.g., NVDRS) to increase awareness, inform strategic interventions, and implement and sustain effective prevention. Expanded partnerships among CDC's ICRCs and state health departments are an important public health strategy to implement and evaluate comprehensive prevention strategies that

BOX. Examples of guidelines for media and online reporting on suicide

- Inform audience without using sensationalized headlines and language.

- Minimize prominence by avoiding prominent placement and repetition of stories.

- Avoid providing detailed information about the method, location of suicide, and information a person might have left in a note.

- Exercise caution when using photographs or video footage by avoiding images of method, location, grieving family and friends, memorials, and funerals.

- Inform that most, but not all, persons who die by suicide exhibit warning signs and provide examples of warning signs (e.g., talking about wanting to die, increased use of drugs or alcohol, or mood changes).

- Report on suicide as a public health issue rather than in a style similar to reporting crimes.

- Provide advice from suicide prevention experts rather than first responders.

- Provide information about where to seek help.

- Use terms, such as "died by suicide" or "killed him/ herself" rather than referring to suicide as "successful" or "unsuccessful."

Sources: http://reportingonsuicide.org/ and http://www.who.int/ mental_health/prevention/suicide/resource_media.pdf. 
reduce risk factors, increase interventions for suicidal behavior, and reduce access to lethal means by persons at greatest risk for suicide. By bringing together a public and mental health approach to suicide prevention, suicides can be prevented.

${ }^{1}$ Division of Violence Prevention, National Center for Injury Prevention and Control, CDC; ${ }^{2}$ Injury Control Research Center for Suicide Prevention, University of Rochester Medical Center, New York; ${ }^{3}$ Colorado Department of Public Health \& Environment; ${ }^{4}$ Suicide Prevention Resource Center and Education Development Center, Massachusetts; ${ }^{5}$ Office of the Director, CDC.

Corresponding author: Corinne David-Ferdon, cferdon@cdc.gov, 770-488-0542.

\section{References}

1. CDC. Web-Based Injury Statistics Query and Reporting System (WISQARS). Atlanta, GA: US Department of Health and Human Services, CDC; 2016. http://www.cdc.gov/injury/wisqars/index.html

2. CDC. High school YRBS: youth online. Atlanta, GA: US Department of Health and Human Services, CDC; 2016. https://nccd.cdc.gov/ Youthonline/App/Default.aspx

3. Harris EC, Barraclough B. Suicide as an outcome for mental disorders. A meta-analysis. Br J Psychiatry 1997;170:205-28. http://dx.doi. org/10.1192/bjp.170.3.205

4. New Freedom Commission on Mental Health. Achieving the promise: transforming mental health care in America. Final report. Rockville, MD: US Department of Health and Human Services; 2003. http://govinfo. library.unt.edu/mentalhealthcommission/reports/FinalReport/ downloads/downloads.html

5. US Surgeon General and the National Action Alliance for Suicide Prevention. National strategy for suicide prevention: goals and objectives for action. Washington, DC: US Department of Health and Human Services, US Surgeon General and the National Action Alliance for Suicide Prevention; 2012. http://www.surgeongeneral.gov/library/reports/ national-strategy-suicide-prevention/index.html

6. Blair JM, Fowler KA, Jack SPD, Crosby AE. The National Violent Death Reporting System: overview and future directions. Inj Prev 2016;22(Suppl 1):i611. http://dx.doi.org/10.1136/injuryprev-2015-041819
7. Lyons BH, Fowler KA, Jack SP, Betz CJ, Blair JM. Surveillance for violent deaths-National Violent Death Reporting System, 17 states, 2013. MMWR Surveill Summ 2016;65(No. SS-10). http://dx.doi. org/10.15585/mmwr.ss6510a1

8. Caine ED. Forging an agenda for suicide prevention in the United States. Am J Pub Health 2013;103:822-9. http://dx.doi.org/10.2105/ AJPH.2012.301078

9. Knox KL, Litts DA, Talcott GW, Feig JC, Caine ED. Risk of suicide and related adverse outcomes after exposure to a suicide prevention programme in the US Air Force: cohort study. BMJ 2003;327:1376-80. http://dx.doi.org/10.1136/bmj.327.7428.1376

10. Mishara BL, Martin N. Effects of a comprehensive police suicide prevention program. Crisis 2012;33:162-8. http://dx.doi. org/10.1027/0227-5910/a000125

11. Center for the Study and Prevention of Violence. Blueprints for healthy youth development. Boulder, CO: University of Colorado Boulder, Institute of Behavioral Science, Center for the Study and Prevention of Violence; 2016. http://www.blueprintsprograms.com/

12. Wyman PA, Brown CH, LoMurray M, et al. An outcome evaluation of the Sources of Strength suicide prevention program delivered by adolescent peer leaders in high schools. Am J Public Health 2010;100:1653-61. http://dx.doi.org/10.2105/AJPH.2009.190025

13. National Action Alliance for Suicide Prevention, Research Prioritization Task Force. A prioritized research agenda for suicide prevention: an action plan to save lives. Rockville, MD: National Action Alliance for Suicide Prevention, Research Prioritization Task Force; 2014. http:// actionallianceforsuicideprevention.org/task-force/research-prioritization

14. Sonneck G, Etzersdorfer E, Nagel-Kuess S. Imitative suicide on the Viennese subway. Soc Sci Med 1994;38:453-7. http://dx.doi. org/10.1016/0277-9536(94)90447-2

15. Gould MS, Cross W, Pisani AR, Munfakh JL, Kleinman M. Impact of applied suicide intervention skills training on the National Suicide Prevention Lifeline. Suicide Life Threat Behav 2013;43:676-91. http:// dx.doi.org/10.1111/sltb.12049 